\title{
Brazil: towards sustainability and equity in health
}

\author{
Commented by: Carla Cardoso ${ }^{1}$
}

Kleinert S, Horton R. Brazil: towards sustainability and equity in health. Lancet. 2011;377(9779):1721-2.

The issues sorrounding health care usually generate great discussions, which, in many cases, are divided between distinct poles: on one side, the one that elaborates public policies, and, on the other, the one that uses and depends exclusively on this system. The defense for improvement in health care is a hystorical struggle, and the Brazilian society has made some important achievements in recent years. However, it is important to emphasize that the health system currently used in the country, the Unified Health System (SUS), besides its difficulties and needs, is considered by many other countries a model of health assistance.

Given this scenario and some prerogatives that make the Unified Health System (SUS) a model of health assistance, The Lancet has published, in May 2011, a special edition about the history and perspectives of Public Health in Brazil. This edition counted with the participation of renowned Brazilian researchers who discussed, in six articles, the internal and external issues of public health policies in the country, as well as their perspectives and advances.

However, maybe the greatest legacy of this edition was the contribution provided by the editors of the journal, who approached, in three editorials, issues regarding the model of equity, the public participation, and the need for a more effective policy of international cooperation. These comments evidence how much a "foreign" view of our Unified Health System (SUS) might benefit its process of improvement and growth, as well as guarantees that this system has, in its origins, a wide and participative conception.

One of the editorials, written by Kleinert and Horton, focused on the issues regarding the sustainability and equity of the Unified Health System (SUS), showing that the success of public health policies depends on the quality of the administrative process that precedes its realization and implantation, on the information regarding the changing reality, as well as on the technical capacity and discipline of the public servers, and the social participation and control.
The text traces the background of the current Brazilian political scene, mentioning the hystorical change with the first woman in power and its relationship with the economic growth, even addressing the issues regarding the newly discovered oil fields in the country. This contextualization helps the reflection about the current moment of economic growth and the gains acquired in recent years concerning public health issues. It considers that the pillars of the SUS - universality and equity enshrined by the 1988 constitution are an important milestone and differential within a process of change in posture regarding health care in the country, substituting the biomedic model, used in many countries, by a new model that advocates equity and allows, mainly, the access of all socioeconomic levels.

This concept allows the inclusion of issues related to the social determinants of health, education, poverty reduction, and preventive measures in the broader context of health as a right. The authors emphasize that this process is triggered by the possibility of community participation at all administrative levels, and might be considered as having a strategic importance in this system, which combines health and education.

Another important point is that this process of improvement in health care needed to break with the "old concepts and practices" of assistential actions, allowing the integralization between attention and care for issues of the contemporary world, answering the demands that, in a fragmented manner, would not be possible. However, one needs to consider that, although this model has existed for over two decades, it is still necessary to modify the sporadic character of actions, by reworking many of the current practices.

Therefore, the authors believe that this model of action has guaranteed the improvement of access to primary and emergency care, and that the emphasis of health as a political right, along with the high level of social engagement, might be an important focus of attention of other countries in order to solve their problems.

(1) Undergraduate Program in Speech-Language Pathology and Audiology, Universidade do Estado da Bahia - UNEB - Salvador (BA), Brazil. 